\title{
The Role of Clinical Pathways on Healthcare Quality Improvement in Hospitals for Patient Undergoing Total Hip Replacement
}

\author{
Savka Štrbac, ${ }^{1,2}$ Severin Rakić, ${ }^{2}$ Vesna Vujić Aleksić, ${ }^{3}$ Ranko Škrbić1
}

\section{Abstract}

Background: Clinical pathways are important tools to achieve better quality of care and to reduce the costs for healthcare system. The total hip replacement (THR) is among the most expensive procedures in health system and the number of these operations has greatly increased in the past decade in the Republic of Srpska.

Aim: The aim of the present study was to determine how the implementation of a clinical pathway for THR can influence the length of stay and postoperative complications in hospitals in the Republic of Srpska.

Methods: This prospective and comparative study was performed on 2,485 patients who underwent the THR over a 3-year-period in 2012 (prior to the introduction of the clinical pathways, baseline), in 2013 (first evaluation period) and in 2014 (second evaluation period), one and two years after its implementation, respectively. The study was conducted in 10 hospitals in the Republic of Srpska, where the effects of the clinical pathways on length of stay and postoperative complications after THR were measured.

Results: The introduction of THR clinical pathways significantly decreased the length of stay in hospital from $14.53 \pm 7.03$ days measured at baseline, to $12.79 \pm 4.81$ days and $11.19 \pm 4.11$ days at first and second evaluation period, respectively. At the same time, the number of early postoperative complications such as death and venous thromboembolism significantly decreased in both groups, while the number of dislocations, as parameter of late complications, decreased just after the second evaluation period. For all other complications, such as revision procedures, infections and periprosthetic fracture, there were no statistical differences after the implementation of clinical pathways.

Conclusion: The introduction of clinical pathways was successful in reducing the length of stay in hospitals as well as the postoperative complications after THR.

Key words: clinical pathways, total hip replacement, length of stay, quality of care.
(1) Centre for Biomedical Research, Faculty of Medicine, University of Banja Luka, Banja Luka, the Republic of Srpska, Bosnia and Herzegovina.

(2) Public Health Institute of the Republic of Srpska, Banja Luka, the Republic of Srpska, Bosnia and Herzegovina.

(3) Agency for Certification, Accreditation and Healthcare Quality Improvement of the Republic of Srpska (ASKVA), Banja Luka, the Republic of Srpska, Bosnia and Herzegovina.

\section{Correspondence:}

SAVKA ŠTRBAC

E: savka.simic@hotmail.com

M: +387 65529406

\section{ARTICLE INFO}

Received: 2 June 2020 Revision received: 7 June 2020 Accepted: 8 June 2020

\section{Introduction}

Total hip replacement (THR) is an orthopaedic surgery performed to reduce pain and improve function in patients suffering from hip fractures or hip arthritis. In recent decades, there has been a growing need for this procedure, which is the result of an aging of population, an increase in the prevalence of osteoarthritis and the presence of obesity epidemic. ${ }^{1}$ If this trend continues in the future, an even greater increase in the need for intervention such as THR can be expected. ${ }^{2}$

Although the THR is a cost-effective treatment, both from the clinical and patients' perspective, this operation produces a significant cost for hos- 
pitals, which could be a critical issue due to limited funds available for healthcare systems. Having that in mind, it would be extremely important to introduce certain instruments for costs control without compromising the quality of patient care. There are several strategies that are being applied for quality of care improvement in hospitals, but introduction of clinical pathways, also known as care pathways (CP), have been seen as the most successful instrument for quality of care improvement and reduction of costs in healthcare worldwide. ${ }^{3,4}$ There is a considerable amount of evidence that implementation of $\mathrm{CP}$ can reduce both the length of stay in hospital and cost of treatment, without undesirable outcomes and postoperative complications..$^{5-9}$ However, these studies have never been performed in health system of the Republic of Srpska.

Vanchaecht et $\mathrm{al}^{10}$ studied the effects of CPs on total knee arthroplasty in a large teaching hospital in Belgium and concluded that CPs effectively reduce the length of stay (LOS) by $33 \%$ without affecting the short-term functional outcomes. Results of studies conducted in hospitals in the Netherlands showed that using a CP approach for patients with hip fracture tends to be more effective than usual care. ${ }^{11}$ In another study conductted in 11 US hospitals, it was demonstrated that the implementation of THR clinical pathway was successful in reducing the patient's LOS in hospital, as well as with increasing discharges to home what consequently led to cost reduction. ${ }^{12}$

The aim of this study was to determine how the implementation of a CP for THR can influence the LOS and postoperative complications in hospitals in the Republic of Srpska, Bosnia and Herzegovina.

\section{Methods}

\section{Study period}

This prospective and comparative study was performed in all patients who underwent the THR over a 3-year period. This period covered the 12 months (January - December 2012) prior to the introduction of the CPs, and the 24 months follow-up period (January 2013 - December 2013 and January 2014 -December 2014) after its implementation.

\section{Development and implementation of the clini-} cal pathways

The CPs were developed by a multidisciplinary team of healthcare professionals involved in the THR patients care in accordance with recommendations of international clinical guidelines. The team was comprised of an orthopaedic surgeon, a clinical quality coordinator, a chief nurse and a physiotherapist. The objectives of this CP were the reduction of LOS in hospital and the reduction in post-operative complications. In this regard, the following key interventions and outcomes were defined: (1) admission criteria; (2) admission date; (3) prophylactic use of antibiotics; (4) thromboembolic prophylaxis; (5) start of physiotherapy procedure on postoperative day 1 ; (6) discharge criteria and (7) discharge date. The structure and the identification of other activities in the process (nursing assessment, evaluation by a physiotherapist, daily monitoring, etc) in addition to responsibility for these activities were left to each hospital to be adapted according to organisational and working conditions.

\section{Sample size}

The study was conducted in 10 hospitals in the Republic of Srpska, at the departments for orthopaedic surgery that regularly perform THR procedure. The clinical pathway project began in January 2013. Each patient underwent the THR gave the informed consent to participate in the study. Before the implementation of the $\mathrm{CP}$, a baseline measurement was performed from January 2012 to December 2012 in one group of patients ( $\mathrm{n}=$ 849; 288 men and 561 women). First evaluation of the CP was done from January 2013 to December 2013 in a second group of patients $(n=802$; 284 men and 518 women). Second evaluation was done from January 2014 to December 2014 in a third group of patients $(n=834 ; 262$ men and 572 women). Therefore, the total number of patients included in this study was 2,485 . Patients excluded from this study were those with THR revision (replacement of previously fitted prosthesis), as well as the patients suffering from cancer as a primary diagnosis.

\section{Indicators}

To measure the effects of CPs the two groups of indicators were defined, known as the process and the outcome indicators. The process indicator was measured by the average LOS in hospital, while the outcome indicators were measured through early complications, as a rate of various surgical complications within 90 days (venous thromboembolism, death) and late complica- 
tions, as the outcomes within one year after surgery (infection, dislocation, periprosthetic fracture, revision of surgery). ${ }^{13}$

Measurements were taken at three time points: the baseline measurement, the second measurement taken 12 months after the implementation of the pathway and the third measurement taken 24 months after the implementation of the pathway. The outcomes were registered during the hospital stay and throughout the follow-up period. For all three groups of patients the follow-up period was 1 year after surgery.

\section{Data collection and monitoring}

Data collection and monitoring were carried out continuously, by entering data into the on-line application form for routine monitoring of quality indicators designed by the Agency for Certification, Accreditation and Healthcare Quality Improvement of the Republic of Srpska (ASKVA). The electronic system for collection, monitoring, analysis and presentation of quality indicators results in hospitals of the Republic of Srpska has been successfully introduced at the beginning of 2011 as an online application. The responsible hospital staff enters the required information from CP for all patients no later than on the fifth day of each month for the previous month. The reliability of data was adequate since data were used to categorise patients according to the Diagnosis Related Group system (DRG) and the consequent payment of each hospital by the Health Insurance Fund.

\section{Statistical analyses}

Data analysis were performed using the commercial statistical software SPSS Statistics 18. Verification of the normality of parameters distribution was performed using the Kolmogorov-Smirnov test. Statistical significance between groups was verified using the Kruskal-Wallis test and the post hoc comparison by using the Mann-Whitney test. Individual variables were presented in the form of frequency of individual characteristics (categories) and the statistical significance of the differences is determined using the chi-square test. The significance level was set at $\mathrm{p}<0.05$. $^{14}$

\section{Results}

The study included a total of 2,485 patients with performed THR. The first group, before the CP was implemented, included 849 patients with a mean age of 70 . The second group of 802 patients, with an average age of 68 , underwent the primary THR based on CP and was assessed during the first evaluation period. Eight hundred thirty-four patients, with a mean age of 68 , had THR surgery based on CP and was assessed during second evaluation period. All three groups were similar regarding the age and gender (Table 1 ).

\section{Average length of stay}

The implementation of THR pathway corresponded with the decreased LOS in hospitals by 22.9 $\%$ during the overall observational period (first group compared to second evaluation group; $p$ $<0.001$ ). Compared to the years of observation (2012-2013 and 2012-2014), the average length of stay decreased by each year (12.79 and 11.19 days, respectively; Table 1).

Table 1: Demographics and clinical data regarding years of observation

\begin{tabular}{|c|c|c|c|}
\hline Parameters & $\begin{array}{l}\text { Baseline } \\
\text { evaluation } \\
(n=849)\end{array}$ & $\begin{array}{l}\text { First } \\
\text { evaluation group } \\
(n=802)\end{array}$ & $\begin{array}{l}\text { Second } \\
\text { evaluation group } \\
(n=834)\end{array}$ \\
\hline Age & $70.69 \pm 23.69$ & $67.92 \pm 25.11$ & $68.60 \pm 23.64$ \\
\hline \multicolumn{4}{|l|}{ Gender, $\mathbf{n}(\%)$} \\
\hline female & 561 (66.08) & 518 (64.59) & 572 (68.59) \\
\hline male & $288(33.92)$ & $284(35.41)$ & $262(31.41)$ \\
\hline $\begin{array}{l}\text { Average } \\
\text { length of stay }\end{array}$ & $14.53 \pm 7.03$ & $12.79 \pm 4.81^{\star}$ & $11,19 \pm 4.11^{*}$ \\
\hline
\end{tabular}

The differences between the average LOS were significant in both evaluation periods. The average LOS was significantly decreased in both observational periods; 2012 to 2013 ( $p<0.001$ ), as well as 2012 to 2014 ( $<$ 0.001) (Table 2).

Table 2: Paired statistical comparison of average length of stay data according to the evaluation period

\begin{tabular}{|c|c|c|}
\hline Evaluation period & $z$ value & $\mathrm{p}$ value \\
\hline First evaluation (2012 vs 2013) & 6.04 & $\mathrm{p}<0.001$ \\
\hline Second evaluation (2012 vs 2014) & 13.57 & $p<0.001$ \\
\hline
\end{tabular}

\section{Postoperative complications}

The implementation of CPs significantly reduced the total number of postoperative complications in the second and third group of patients; from 134 at baseline (first group) to 92 (second group) and 79 (third group) measured at the first and second evaluation period, respectively. In the first group, $15.9 \%$ of patients had at least one postoperative 
Table 3: The rates of postoperative complications after THR

\begin{tabular}{|c|c|c|c|c|c|c|}
\hline A. Postoperative complications & \multicolumn{2}{|c|}{$\begin{array}{l}\text { Baseline (2012) } \\
n=849\end{array}$} & \multicolumn{2}{|c|}{$\begin{array}{l}\text { First evaluation (2013) } \\
n=802\end{array}$} & \multirow[t]{2}{*}{$\chi^{2}$} & \multirow[t]{2}{*}{ p-value } \\
\hline Early complications & $\mathbf{n}$ & $\%$ & $\mathbf{n}$ & $\%$ & & \\
\hline Death & 57 & 6.71 & 32 & 3.99 & 5.999 & 0.014 * \\
\hline Venous thromboembolism & 28 & 3.30 & 12 & 1.50 & 5.663 & $0.017^{*}$ \\
\hline \multicolumn{7}{|l|}{ Late complications } \\
\hline Revision procedures & 15 & 1.77 & 24 & 2.99 & 2.687 & 0.101 \\
\hline Infections & 9 & 1.06 & 9 & 1.12 & 0.015 & 0.903 \\
\hline Dislocation & 13 & 1.53 & 4 & 0.50 & 3.360 & 0.067 \\
\hline Periprosthetic fracture & 13 & 1.53 & 11 & 1.37 & 0.073 & 0.786 \\
\hline Total of complications & 135 & 15.9 & 92 & 11.47 & 6.456 & 0.011 \\
\hline B. Postoperative complications & \multicolumn{2}{|c|}{$\begin{array}{l}\text { Baseline (2012) } \\
n=849\end{array}$} & \multicolumn{2}{|c|}{$\begin{array}{l}\text { First evaluation (2014) } \\
n=834\end{array}$} & $\chi^{2}$ & p-value \\
\hline Early complications & n & $\%$ & n & $\%$ & & \\
\hline Death & 57 & 6.71 & 27 & 3.24 & 10.722 & $0.001 * \star *$ \\
\hline Venous thromboembolism & 28 & 3.30 & 11 & 1.32 & 7.280 & $0.006^{\star *}$ \\
\hline \multicolumn{7}{|l|}{ Late complications } \\
\hline Revision procedures & 15 & 1.77 & 21 & 2.52 & 1.134 & 0.286 \\
\hline Infections & 9 & 1.06 & 5 & 0.60 & 1.082 & 0.298 \\
\hline Dislocation & 13 & 1.53 & 2 & 0.24 & 7.943 & 0.004 * \\
\hline Periprosthetic fracture & 13 & 1.53 & 13 & 1.56 & 0.002 & 0.963 \\
\hline Total of complications & 135 & 15.9 & 79 & 9.47 & 15.092 & 0.001 \\
\hline
\end{tabular}

complication and the most frequent one within 90 days after surgery was death, which occurred in 57 of all cases $(6.71 \%)$. During the first evaluation period, $11.47 \%$ of patients in second group had at least one of postoperative complications and the most common one within 90 days after surgery in this period was also death (32 cases; $3.99 \%)$. At the second evaluation period complications were observed in $9.47 \%$ of patients in the third group and the most common one within 90 days after surgery was again death, but that number was significantly lower than in the previous two groups (27 cases; $3.24 \%$ ). The incidence of other postoperative complications observed in all three groups are presented in Table 3.

For each of the early observed complications there were comparative differences in terms of their reduction, from baseline to the first year of observation, but the statistically significant differences were present only for two major complications such as death and venous thromboembolism $(\mathrm{p}<0.05)$. However, comparing the impact of CPs on post-operative complications after two years of its implementation, the difference was even more significant, particularly in complications such as: death $(\mathrm{p}<0.001)$, venous thromboembolism $(\mathrm{p}<0.01)$ and dislocation $(\mathrm{p}<0.05)$, (Table 3).
Concerning the late postoperative complications there was no significant improvement after the first and second evaluation periods, although the number of revision procedures even increased, but not significantly (Table 3).

\section{Discussion}

The present study evaluated the role of CPs on quality of care for patients undergoing the THR surgical procedure. The implementation of CPs significantly decreased the LOS by $22.9 \%$. Although the LOS in this study has been decreased, it is still longer than in other hospitals as it was confirmed in similar studies, mainly from USA and Europe. ${ }^{5,7,10,11,15}$ It is well known that CPs contribute to reducing the LOS in general, the same result in terms of the existence of a positive relationship between CPs and reduced hospital stay was also observed for patients with THR surgery. ${ }^{4}$, ${ }^{5}$ Beside the improvement of process indicators, the reduced number of postoperative complications is the most important finding of this study confirming that the full implementation of the CPs significantly improved the healthcare quality in the hospital settings. Postoperative physical rehabilitation is a very important component in 
the postoperative recovery of patients after THR. The CP in this study includes early rehabilitation which also contributes to faster discharge from the hospital, followed by a process of further rehabilitation at a rehabilitation hospital or at a community-based rehabilitation (CBR) centre. Timely discharge from the hospital and subsequent referral to rehabilitation centres is another value of clinical pathways because they represent a good logistical support throughout the process.

Indicators of treatment outcomes were significantly improved after the introduction of CPs. Most importantly, the mortality significantly decreased from $6.71 \%$ at the baseline evaluation to $3.24 \%$ at the second evaluation. Similarly, the frequency of another two important postoperative complications, venous thromboembolism and dislocation, also decreased due to the implementation of CPs. However, this positive effect can simultaneously lead to some negative effects such as long-term complications. The ultimate goal of CPs is to optimise the quality and certainly not only to decrease the length of stay. For example, Mauheran et al. found that implementation of a CPs decreased the length of hospital stay, but at the same time it increased the rate of dislocations following THR surgery, underscoring the need to consider the long-term effects of CPs. ${ }^{16}$

A systematic review done by Mufarrih et al showed that there is a positive effect of hospital volume on outcomes following THR, that is, "high-volume" hospitals had superior outcomes compared with "low-volume" hospitals (LOS, early and late postoperative complications).$^{17}$ Establishing a system for measurement and monitoring the process of providing health care, as well as the system for their improvement and in accordance with the defined Deming principles of quality, it is possible to achieve improvements in the "low volume" hospitals. In other words, implementing the CPs taken from the experiences of "high volume" hospitals can realise the benefit for the wider population of patients..$^{18}$ This study showed that the implementation of CPs can reduce the unwanted deviations and process variations for complex interventions such as THR allowing "low-volume" hospitals to achieve better quality of care and help "high-volume" hospitals to improve their quality.

The present study has some limitations. First, the patient sample is large enough, but the baseline measurement occurred a year before the CPs were implemented. Therefore, it cannot be excluded that some of the observed improvements represent a natural drift toward higher performance. A different study design, such as a randomised controlled trial, could improve the strength of these findings. Another limitation of the study is the lack of measurement of patient satisfaction. The combination of outcome indicators with patient satisfaction could provide more accurate information about the quality of care which is achieved by implementing CPs.

In addition, the introduction of CPs does not necessarily have a positive effect on all patient-related outcomes. In contrast, cost-effectiveness from the point of view of health care providers may even be extremely reduced, as indicated by the research of Krummenauer et $\mathrm{al}^{19}$ and Cochrane systematic review and meta-analysis by Rotter et al. ${ }^{5}$ This study did not include the cost implications of the implementation of CPs, which would certainly be desirable for future research in the field of clinical pathways.

\section{Conclusion}

The introduction of CPs in hospitals in the Republic of Srpska significantly reduced the LOS in hospital and also reduced the postoperative complications in patients after THR. Significant improvements in different groups of patients suggest that the implementation of the CPs does have an impact on the quality of care.

\section{Acknowledgements}

None.

\section{Conflict of interest}

None.

\section{References}

1. King LK, March L, Anandacoomarasamy A. Obesity \& osteoarthritis. Indian J Med Res 2013;138(2):185-93.

2. Singh JA, Yu S, Chen L, Cleveland JD. Rates of total joint replacement in the United States: future projections to 
2020-2040 using the national inpatient sample. J Rheumatol 2019;46(9):1134-40.

3. Barbieri A, Vanhaecht K, Van Herck P, Sermeus W, Faggiano F, Marchisio S, et al. Effects of clinical pathways in the joint replacement: a meta-analysis. BMC Med 2009 Jul 1;7:32. doi: 10.1186/1741-7015-7-32.

4. Garson L, Schwarzkopf R, Vakharia S, Alexander B, Stead $\mathrm{S}$, Cannesson $\mathrm{M}$, et al. Implementation of a total joint replacement-focused perioperative surgical home: a management case report. Anesth Analg 2014;118(5):1081-9.

5. Rotter T, Kinsman L, James E, Machotta A, Willis I, Snow $\mathrm{P}$, et al. The effects of clinical pathways on professional practice, patient outcomes, length of stay, and hospital costs: Cochrane systematic review and meta-analysis. Eval Health Prof 2012;35(1):3-27.

6. Asmirajanti M, Syuhaimie Hamid AY, Hariyati TS. Clinical care pathway strengthens interprofessional collaboration and quality of health service: a literature review. Enferm Clin 2018; 28 Suppl 1:240-4.

7. Svenøy S, Watne LO, Hestnes I, Westberg M, Madsen JE, Frihagen F. Results after introduction of a hip fracture care pathway: comparison with usual care. Acta Orthop 2020;91(2):139-45.

8. Scaria MK. Role of care pathways in interprofessional teamwork. Nurs Stand 2016; 24;30(52):42-7.

9. Lawal AK, Groot G, Goodridge D, Scott S, Kinsman L. Development of a program theory for clinical pathways in hospitals: protocol for a realist review. Syst Rev 2019;8(1):136. doi: 10.1186/s13643-019-1046-0

10. Vanhaecht K, Sermeus W, Tuerlinckx G, Witters I, Vandenneucker $\mathrm{H}$, Bellemans J. Development of a clinical pathway for total knee arthroplasty and the effect on length of stay and in-hospital functional outcome. Acta Orthop Belg 2005;71:439-44.

11. Kalmet PH, Koc BB, Hemmes B, Ten Broeke RH, Dekkers G, Hustinx $P$, et al. Effectiveness of a multidisciplinary clinical pathway for elderly patients with hip fracture: a multicenter comparative cohort study. Geriatr Orthop Surg Rehabil 2016;7(2):81-5.
12. Featherall J, Brigati DP, Faour M, Messner W, Higuera CA. Implementation of a total hip arthroplasty care pathway at a high-volume health system: effect on length of stay, discharge disposition, and 90-day complications. J Arthroplasty 2018;33(6):1675-80.

13. Ravi B, Jenkinson R, Austin Peter C, Croxford R, Wasserstein D, Escott B, et al. Relation between surgeon volume and risk of complications after total hip arthroplasty: propensity score matched cohort study. BMJ 2014;348:g3284. doi: 10.1136/bmj.g3284.

14. Komić J, Bokonjić D, Rančić N. [Selected methods of statistical analysis for biomedical research]. Banja Luka: Faculty of Medicine, University of Banja Luka; 2018. Serbian.

15. Schwarzkopf R, Zamansani T, Houng M, Bridgeman T. The effect of a clinical pathway strategy for managing care in total joint replacement: the impact on perioperative outcomes. J Clin Exp Orthop 2016;2:11. doi: 10.4172/24718416.100011.

16. Mauerhan DR, Lonergan RP, Mokris JG, Kiebzak GM. Relationship between length of stay and dislocation rate after total hip arthroplasty. J Arthroplasty 2003;18(8):963-7.

17. Mufarrih SH, Ghani MOA, Martins RS, Qureshi NQ, Mufarrih SA, Malik AT, et al. Effect of hospital volume on outcomes of total hip arthroplasty: a systematic review and meta-analysis. J Orthop Surg Res 2019;14(1):468. doi: 10.1186/s13018-019-1531-0

18. Koenig KM, Bozic KJ. Orthopaedic Healthcare Worldwide: The role of standardization in improving outcomes. Clin Orthop Relat Res 2015;473:3360-3.

19. Krummenauer F, Guenther KP, Kirschner S. Cost effectiveness of total knee arthroplasty from a health care providers' perspective before and after introduction of an interdisciplinary clinical pathway - is investment always improvement? BMC Health Serv Res 2011 Dec 14;11:338. doi: 10.1186/1472-6963-11-338. 